\title{
Examining Human Resource Competencies and Their Relationship to the Success Factors of HR Profession
}

\author{
Choi-Sang Long
}

School of Business \& Management, Southern College Malaysia

Email: cslong_1@yahoo.com

Received October $4^{\text {th }}, 2008$; revised November $11^{\text {th }}, 2008$; accepted November $25^{\text {th }}, 2008$.

\begin{abstract}
This study examines competencies of Human Resource (HR) professionals in the manufacturing companies of Malaysia. The Human Resource Competency Survey (HRCS) model is used in this study. The competencies that are examined in this study are business knowledge, strategic contribution, HR delivery, personal credibility and HR technology. All these competencies will be tested whether or not they are significantly related to a firm's performance. Furthermore, researcher wanted to study the relationship of these competencies with variables such as experience, education level, firm's size and salary of the sample. The sample employed here consists of HR professionals from Malaysian manufacturing companies in Johor, the southernmost state of Malaysia.
\end{abstract}

Keywords: human resource, competencies, manufacturing, success factors, performance

\section{Introduction}

Human resource professionals needed to function strategically. To play more critical roles more effectively, HR professional must master the necessary competencies, and that mastery of HR knowledge comes only from being familiar with the concepts, language, logic, and practices of HR that are the result of research and training. Furthermore, mastery of the above abilities comes from being able to apply the knowledge within specific business settings [1].

Nowadays, competencies are used in many facets of human resource management, ranging from individual functions such as recruitment and performance management to organizational strategic planning and design of organizational structure and culture. HR competencies are said to be a set of characteristics contributing to the effective HR performance that enables an organization to carry out its business strategies in a competitive market. However, many HR executives are not invited to the strategic planning table because they have failed to display the required competencies [2]. In fact, it is suggested that the competency level of the HR manager has an influence on whether he or she is able to get into the executive board chamber [3].

\section{Review of the Literature}

There are several major studies available on HR competencies [4]. One study surveys 3000 HR professionals, consultants, line executives and academicians. That study reports that line executives thought that computer literacy was the most critical HR competence; while academicians argue that a broad knowledge of and a clear vision for HR were the most important issues, and consultants believe that ability to change things is the most important factor in the excellent or HR performance. Another study, examining $300 \mathrm{HR}$ professionals from various sectors, establishes a set of core HR competencies consisting of leadership style, management intuition, functional abilities and personal attributes [5]. One of HR competency surveys suggests that HR professionals needed to be more knowledgeable about financial management, external competition and customer demands [6].

The survey data of the Human Resource Competency Study (HRCS) were collected in 2003 under the initiative of the University of Michigan. The study was carried out online (web-based). The respondents of the European HRCS were HR professionals and line managers of multinational companies located in Europe [7]. In this survey, five domain factors emerged as making a difference in terms of performance. The domains are as follows:

\section{1) Strategic Contribution}

High-performing companies have HR professionals involved in the business at a strategic level. These HR professionals manage the culture, facilitate rapid change, and are involved in the strategic decision making and create market-driven connectivity of the operation [7]. In this competency area, culture management, rapid change efforts, and a business partner role along with customer focus emerged as important factors for HR professionals, 
making their impact on their organizations' financial performance significant [8].

\section{2) Personal Credibility}

HR professionals must be credible to both their HR counterparts and the business line managers whom they serve. They need to promise and deliver results and establish a reliable track record. Furthermore, working well with others by building good relationship is vital in developing the ability to work together with others effectively. In addition, HR professionals must have effective writing and verbal communication skills [7]. The findings of the study by [7] correspond with the prior research of [9], who found that that the personnel directors require professional competence in social skills to develop effective interpersonal relations with other board directors. This is one of the competencies of personal credibility.

\section{3) HR Delivery}

HR professionals deliver both traditional and operational HR activities to their business in four major categories. First, by designing developmental programs and challenging work experiences. This is done by offering career planning services, and facilitating internal communication processes. These efforts include both individual development as well as organisation-wide development. Second, by structuring and HR measurement: restructuring the organisation, measuring impact of HR practices, and managing global implications of HR practices. Third, by attracting, promoting, retaining, and out-placing appropriate people. Finally, by performance management in terms of designing performance-based measurements and reward systems and providing competitive benefit packages [7].

\section{4) Business Knowledge}

To become key players in the organisation, HR professionals must understand the business or industry of the company they serve. Key areas of knowledge include applied understanding of the integrated value chain (how the firm horizontally integrates) and the firm's value proposition (how the firm creates wealth). The labour factor, representing institutional constraints such as labour legislation, is the third factor that constitutes the domain of business knowledge [7]. Human resources professionals must understand how their business or agency operates. This includes the organization's strategy, how the organization makes money or achieves its primary purpose, its technological processes and organizational capabilities, etc. [10].

\section{5) HR Technology}

HR professionals need to be able to leverage technology for HR practices and use e-HR/web-based channels to deliver value to their customers [12]. [12] further argues that the pace of technological innovation will continue to accelerate. HR can take advantage of these changes by automating HR processes and becoming more effective in communicating with its internal /external customers. More importantly, by absorbing the latest tech- nology, HR can project a forward looking image that will help it earn the respect of skeptical colleagues. According to a recent survey by Society for Human Resource Management, the top workplace trend identified was technology [12].

\subsection{The Relationship between HR Competencies and a Firm's Performance}

Researchers in the field of strategic human resource management have emphasized that human resource practices may lead to higher firm performance and be sources of sustained competitive advantages [13]. Competing in today's tumultuous global economy provides additional challenges to the HR function in creating the expected value to create and sustain competitive advantages. To function effectively, HR professionals must master the necessary competencies, and that mastery of HR knowledge comes from knowing the concepts, language, logic, research, and practices of HR [1]. Furthermore, mastery of these abilities comes from being able to apply that knowledge to specific business settings.

[14] have convincingly argued that HR professionals need to become more effective strategic business partners. [15] argue further that HR professionals must make the transition from being strategic business partners to becoming contributors in their organizations. Several studies have shown a positive relationship between certain HR competencies and firm performance [7,13,16,17,18] have stated that there is an emerging group of human resource professionals who see the opportunity to turn human capital strategy into a long-term competitive advantage. They observe that in the 1990s there was a wake-up call for the human resource profession. More than ever, organizations now seek greater creativity and productivity from people. Part of the strategy in being creative and maximizing productivity is to possess the necessary competencies for enabling these outcomes.

The research by Brockbank [1] showed that HR activities positively impact business performance by approximately $10 \%$ (defined as the financial performance of the business over the last three years compared to its major competitors). Strategic contribution accounts for 43 percent of HR total impact on business performance which is almost twice the impact of any other domain. These are all reasons why competencies are being discussed by academicians and practitioners alike as ways of creating sustainable competitive advantages.

A study by [7] indicates the domain of strategic contribution is positively correlated with financial competitiveness, while the domain of HR technology is negatively correlated with this performance outcome. This is not completely in line with the global HRCS findings. In the Europe, the study found only one domain (strategic contribution) to be positively related to financial competitiveness, in contrast to the global results that suggest four out of five domains to be positively linked to finan- 
cial competitiveness. Fourth, all domains reveal relatively high correlations with each other.

\subsection{Relationship between HR Competencies and Success Factors of HR Profession}

In this study, researcher wanted to see if there are any impact on HR professionals' competencies with selected success factors like the working experience, education level, firm's size and salary. [17] study found that salary was significantly related to years of HR experience as well as to self-rated competency in six of the competency areas. The six competency area are delivering HR, technical competence, managing change, understanding business, strategic contribution and accounting. Interestingly, although experience was related to self-ratings of competencies in six areas, education was not related to any of the self-ratings of competence. This result contradicts with [19] study which found that education level of the HR practitioners does influence their competencies. [19] further claim that leading companies, such as General Electric and Amoco, seek entry-level HR/IR practitioners who have the capacity to become strategic business partners and align themselves with the other functions to ensure organizational success. Specifically, those who seek admittance to General Electric's prestigious HR management development program must possess a graduate degree or bachelor's degree from a reputable HR/IR program [20].

[17] study shows the various relationships existing among the core HR strategies, factors leading to improvement in the competencies, impact of education and the competencies on compensation, and the relationship between education and the respective competencies. The results provide a reminder to $\mathrm{HR}$ professionals of the value of graduate degrees and other means of developing higher levels of HR technical competence, understanding the benefits of accounting, marketing, and other different functional areas in effectively developing and implementing HR strategies. By understanding the impact of the competencies on the various organizational practices, there could be a more directed strategy in developing expertise among HR professionals, hence, a more credible and effective function [17].

[21] in their study mention that HR professionals working in small companies may be so focused on solving problems on a daily basis that they have no time for focusing being a strategic business partner. Customer service skills are more important to HR practitioners in large companies. HR Practitioners from small companies gave more importance to organizational skills. Anyway, no differences emerged between upper and middle level managers of their HR competencies in this study. Furthermore, upper managers described the HR department as designing, implementing, and evaluating HR strategies and programs, acting as an internal consultant, supporting line management, and being both a member of the executive management team and a strategic partner with top management. HR professionals from the manufacturing sector reported two roles that HR plays in their companies, that of change agent and outsourcer of HR programs. The study from [21] shows significant differences in the task of HR practitioners from large and small companies. Small companies reported that their HR departments monitored legal compliance and motivated employees and large companies reported that their HR department outsourced HR programs.

\section{The Study}

The purpose of this study is to attempt to understand better the Human Resource (HR) professional's competencies in the manufacturing sector of Malaysia. Furthermore, these finding will be tested in order to determine if they are linked to a firm's performance. In this research, the tool of Human Resource Competency Study (HRCS), which has been designed by Wayne [8], will be used to assess HR competencies among the HR professionals. HR professionals need to endure and overcome many barriers to reach the ultimate goal of becoming a strategic partner in his of her organization. It is hoped that by making this examination, we will be able to develop a realistic picture of the competencies of the HR professionals in the manufacturing firms of Malaysia. Another purpose of this study is to determine the relationship between HR competencies and possible success factors of HR profession eg. experience, education level firm's size and salary.

\section{Research Methodology}

\subsection{Sample}

The sample employed here consists of HR professionals from Malaysian manufacturing companies. All respondents work for manufacturing companies in the southernmost state of Malaysia, Johor. These industries were chosen because of their relatively large. The list of firms in the manufacturing sector was drawn from the "FMM directory of Malaysian Manufacturers 2007." Only firms with at least 50 full-time employees were studied. This is because other studies have shown that firms with smaller employment size are less likely to have HRM departments [22]. Out of the entire list in the directory, the research focused on a sample population in the Southern region of Malaysia (State of Johor). A total of about 300 firms were included in the list for this area. The total number of firms involve in this study are 32 respondents.

\subsection{The Instrument}

The data collection instrument used in this research is the a quantitative methodology with a survey instrument developed based on the five competency domains and 17 competency factors identified in the Human Resource Competency Study (HRSC) [8]. To improve statistical reliability, the HR technology domain was divided into two competency factors; one was operational and one 
strategic. This resulted in 18 competency factors that resided within the five competency domains. A Likert scale was used on the questionnaire with the following ratings: 1-strongly disagree, 2-disagree, 3-moderately agree, 4-agree and 5-strongly agree. The respondent was asked how well they performed the competencies identified in the HRSC. A statement describing each competency factor is listed on the questionnaire. The 18 items in the instrument are arranged in groups of five competency domain.

Firm performance was measured by the self-reported rating of the respondents concerning the indicators of financial and operational performance, sustainability of profits, staffs turnover and the opportunity for growth for staff. A Likert scale was used on the questionnaire with the same rating scale as above. However, for negative questions, the rating procedures are opposite. The respondent was asked to choose the number that accurately represented their firm's performance. There are 5 items in this section that assess a firm's performance. The research used three negative questions to ensure reliability.

No researcher can completely eliminate measurement error, but he or she can reduce it in several ways, such as by conducting a pilot study. If the measurement error is reduced, the reliability of the measurement technique is increased [23]. Therefore, a pilot study was done to test the research instrument in this study. The researcher of this study used Cronbach alpha co-efficient method for this purpose. The result of the reliability test shows that the alpha value base in each domain of the instrument is between 0.62 to 0.89 . Components that are tested are strategic contribution (alpha $=.89)$, personnel contribution (alpha value $=0.67$ ), HR delivery (alpha value $=0.62$ ), Business knowledge (alpha value $=0.76$ ), HR technology (alpha value $=0.88$ ) and firm performance (alpha value=0.86). According to [24], any measurement instrument should have reliability value of more than 0.60 . [23] stressed that a measurement instrument can be considered reliable if the results are consistent from one time to another and that the reliability value is 0.70 or greater. Therefore, from the alpha value obtained, we can conclude that the research instrument is reliable and consistent.

\section{Analysis}

Table 1 show that the top nine ranking HR competency factors are from the domain of personal credibility and HR delivery. The respondents' self-rated competency shows that personal communication, legal compliance, effective relationship and performance management rank above all other factors. It would follow that respondents are most competent in these areas.

HR Professionals need to develop a relationship of trust with their clients, i.e. management team and line managers to instill confidence. These findings show positive development to the HR professionals in Malaysia because personal credibility competency is the foundation for a HR professional to become intimately involved at the strategic level in an organization once given the opportunity. Without this foundation of trust, HR Professionals may very well find themselves excluded from the strategy table. However, this study has

Table 1. Rank order of means of HR competency factors in each domain

\begin{tabular}{|c|c|c|c|c|}
\hline Competency & Factors & Mean & Std. Deviation & Rank \\
\hline \multirow[t]{4}{*}{ Strategic Contribution } & Culture management & 2.91 & 0.89 & 18 \\
\hline & Fast change & 3.06 & 0.95 & 15 \\
\hline & Strategic decision-making & 3.03 & 0.69 & 16 \\
\hline & Market driven connectivity & 2.97 & 0.78 & 17 \\
\hline \multirow[t]{3}{*}{ Personal Credibility } & Achieving results & 4.16 & 0.68 & 7 \\
\hline & Effective relationships & 4.38 & 0.66 & 3 \\
\hline & Personal communication & 4.63 & 0.49 & 1 \\
\hline \multirow[t]{6}{*}{ HR Delivery } & Staffing & 4.31 & 0.78 & 5 \\
\hline & HR development & 4.16 & 0.95 & 8 \\
\hline & Organization structure & 4.28 & 0.85 & 6 \\
\hline & HR measurement & 4.13 & 0.79 & 9 \\
\hline & Legal Compliance & 4.44 & 0.80 & 2 \\
\hline & Performance management & 4.38 & 0.79 & 4 \\
\hline \multirow[t]{3}{*}{ Business Knowledge } & Value chain knowledge & 3.31 & 1.03 & 13 \\
\hline & Value proposition knowledge & 3.44 & 0.88 & 12 \\
\hline & Labor knowledge & 3.53 & 0.88 & 10 \\
\hline \multirow[t]{2}{*}{ HR Technology } & User of technology to deliver HR services & 3.31 & 0.69 & 14 \\
\hline & Strategic HR technology & 3.47 & 0.95 & 11 \\
\hline
\end{tabular}


found that respondents score lowest for strategic contribution competency. Based on competency factors in each domain, all strategic contribution factors score the lowest mean score in terms of mean ranking as shown in Table 1. This shows that HR professionals in Malaysian manufacturing sector are extremely weak in culture management, market driven connectivity, strategic decision-making and fast change. This result is indeed a concern because HR professionals should be able to identify and implement organizational cultures that help firms win the marketplace and successfully implement business strategies. Furthermore, if HR professionals are not able to facilitate change management processes and adapt learning to new change initiatives, they would have problems working with key individuals to ensure decisions are made quickly and to ensure resources are aligned with desired changes [8].

As shown in Table 2, not all HR professional competencies (Strategic Contribution, Business knowledge, Personal credibility, HR delivery and HR technology) have significant correlation with a firm's performance. Competencies such as strategic contribution, business knowledge and HR technology have significant correlation with firm performance. These competences obtained Spearmen's rho value at $0.542(\mathrm{p}<0.01), 0.542(\mathrm{p}<0.01)$ and $0.373(\mathrm{p}<$ 0.05 ). However, no correlation was found between personal credibility and HR delivery in assessing

Table 2. Relationship of HR competencies to firm performance

\begin{tabular}{ccc}
\hline & Spearman's rho analysis & $\begin{array}{c}\text { Firm per- } \\
\text { formance }\end{array}$ \\
\hline $\begin{array}{c}\text { Strategic } \\
\text { contribution }\end{array}$ & Correlation Coefficient & $0.542^{* *}$ \\
Sig. (2-tailed) & 0.001 \\
$\begin{array}{c}\text { Personal } \\
\text { credibility }\end{array}$ & Correlation Coefficient & 0.144 \\
& Sig. (2-tailed) & 0.433 \\
HR delivery & Correlation Coefficient & 0.016 \\
Business & Sig. (2-tailed) & 0.930 \\
knowledge & Correlation Coefficient & $0.542^{* *}$ \\
& Sig. (2-tailed) & 0.001 \\
\hline $\begin{array}{c}\text { HR tech- } \\
\text { nology }\end{array}$ & Correlation Coefficient & $0.373^{*}$ \\
& Sig. (2-tailed) & 0.036 \\
\hline
\end{tabular}

\footnotetext{
* Correlation is significant at the 0.05 level (2-tailed).
}

** Correlation is significant at the 0.01 level (2-tailed). a firm's performance. Both of these competencies obtained a Spearmen's rho value at 0.144 and 0.016 .

This result partially supports the earlier research from [7]. While a study by [7] indicates that the domains of strategic contribution, business knowledge, personal credibility and HR delivery are positively correlated with financial competitiveness, although there is no correlation between HR technology and financial performance.

As shown in Table 3, only two out of five HR competencies have significant correlation with independent variables. HR competencies such personal credibility has significant correlation with $\mathrm{HR}$ experience, education level and salary but show no correlation with the firm's size. Business knowledge competencies have significant correlation with all success factors (HR experience, education level, firm's size and salary).

The findings from this section is supported by the study from [17] that indicates that salary was significantly related to competency such as understanding business knowledge. [17] study also shows that the impact of education and the competencies on compensation. The result provide a reminder to HR professionals of the value of education level such as graduate degrees developing higher levels of HR technical competence, understanding the benefits of accounting, marketing, and other different functional areas in effectively developing and implementing HR strategies. This study also indicates that HR experience is significantly related to HR competencies such as delivering HR, strategic contribution, understanding the business and technical competence.

Table 3. Correlations between HR competencies and HR experience, education level, firm size and salary competencies

\begin{tabular}{|c|c|c|c|c|}
\hline & $\begin{array}{l}\mathrm{HR} \text { ex- } \\
\text { perience }\end{array}$ & $\begin{array}{l}\text { Education } \\
\text { level }\end{array}$ & $\begin{array}{l}\text { Firm's } \\
\text { size }\end{array}$ & Salary \\
\hline $\begin{array}{l}\text { Strategic } \\
\text { contribution }\end{array}$ & 0.185 & 0.078 & 0.326 & 0.138 \\
\hline $\begin{array}{l}\text { Personal } \\
\text { credibility }\end{array}$ & $0.436^{*}$ & $0.549 * *$ & 0.294 & $\begin{array}{c}0.612 \\
* *\end{array}$ \\
\hline HR delivery & 0.174 & 0.011 & 0.231 & 0.244 \\
\hline $\begin{array}{l}\text { Business } \\
\text { knowledge }\end{array}$ & $0.367 *$ & $0.468 * *$ & $0.417^{*}$ & $\begin{array}{c}0.443 \\
*\end{array}$ \\
\hline $\begin{array}{l}\text { HR tech- } \\
\text { nology }\end{array}$ & 0.060 & 0.039 & 0.213 & -0.069 \\
\hline $\begin{array}{l}\text { HR experi- } \\
\text { ence }\end{array}$ & 1.000 & $0.442^{*}$ & $0.669 * *$ & $\underset{* *}{0.676}$ \\
\hline $\begin{array}{l}\text { Education } \\
\text { level }\end{array}$ & $0.442 *$ & 1.000 & 0.430 & 0.613 \\
\hline Firm's size & $0.669 * *$ & $0.430 *$ & 1.000 & $\begin{array}{c}0.576 \\
* *\end{array}$ \\
\hline Salary & $0.676^{* *}$ & $0.613 * *$ & $0.576^{* *}$ & 1.000 \\
\hline \multicolumn{5}{|c|}{$\begin{array}{l}* \text { Correlation is significant at the } 0.05 \\
\text { level (2-tailed). }\end{array}$} \\
\hline \multicolumn{5}{|c|}{$\begin{array}{l}\text { ** Correlation is significant at the } 0.01 \\
\text { level (2-tailed). }\end{array}$} \\
\hline
\end{tabular}


The study from [19] show significant differences in the task of HR practitioners from large and small companies (firm's size). Small companies reported that their HR departments monitored legal compliance (one of the factors in the competency of HR delivery) and large companies reported that their HR department outsourced HR programs. However, this result could not be supported by this research as no significant relationship was found between firm's size and HR delivery.

\section{Discussion}

[14] have argued that HR professionals need to become more effective strategic business partners. [25] argue further that HR professionals must transition from being strategic business partners to becoming contributors in organizations. Given that numerous studies have shown a positive relationship between strategic HRM practices and firm performance, this study sought to identify the competencies needed for HR professionals to become effective business partners and contributor in organizations.

As [26] have shown strategic contribution, personal credibility, HR delivery, business knowledge, and HR technology are all pivotal to HR being effective business partners and players. This study enabled readers to determine the various relationships existing among the core HR strategies, factors leading to improvement in the competencies, impact of education and the competencies on compensation, and the relationship between education and the respective competencies. The results provide a reminder to HR professionals of the value of graduate degrees and other means of developing higher levels of HR technical competence, understanding the benefits of accounting, marketing, and other different functional areas in effectively developing and implementing HR strategies. By understanding the impact of the competencies on the various organizational practices, there could be a more directed strategy in developing expertise among HR professionals, hence, a more credible and effective function.

The findings of this study support notions of [17] and Becker et al. [27] who emphatically stated the need for metrics as a core component of the HR strategy. Although there are many positive results for the HR profession in general from this study, there are clearly many areas that are lacking. To be a true strategic partner and player, HR professionals and other executives of organizations must focus on developing the critical competencies necessary to enhance HR effectiveness and hence maximization of shareholder value.

HR professionals need to be proactive and flexible in their mind set. They should not think that they play only a supportive role but also their contribution can give impact to an organization performance. One major finding of this study is that HR professionals often lack the com- petencies related to business. It is clearly shown that competency such as culture management, market driven connectivity, strategic decision making, rapid adaptability, value-chain knowledge and HR technological know-how are lacking and are among the weakest abilities of a HR professionals in the Malaysian manufacturing sector.

\section{Conclusions}

The findings of this research show that HR professional in the manufacturing companies of the southern region of Malaysia are lacking in business related human resource competencies. This is one of the main barriers to be surmounted if local HR professional are to become strategic partners in their organizations. As this study has shown, these competencies contribute to a firm's effective performance. Therefore, it is vital for HR professional to possess the right competency to improve overall firm's productivity and performance. Furthermore, they must take initiative to excel in many area especially knowledge beyond HR practices. This may be the only road to success for all HR profession in the future.

\section{Acknowledgement}

The author is grateful to Dr. Richard Spear for his valuable comments on this paper. The author also would like to take this opportunity to acknowledge the contribution and generous support of the firms that have participated in this study.

\section{REFERENCES}

[1] W. Brockbank, D. Ulrich, and R. Beatty, "The professional development: Creating the future creators at the university of michigan business school," Human Resource Management, 38(2), pp. 111-118, 1999.

[2] J. B. Barney and P. M. Wright, "On becoming a strategic partner: The role of human resources in gaining competitive advantage," Human Resource Management, pp. 37 (1): 31-46, 1998.

[3] J. Selmer and R. Chiu, "Required human resources competencies in the future: A framework for developing HR Executives in Hong Kong," Journal of World Business (39), pp. 324-336, 2004.

[4] N. Khatri and P. Budhwar, "A study of strategic HR issues in an Asian context," Personnel Review 31 (2), pp. 166-88, 2002.

[5] K. E. Scanlan, "University HRM curriculum and HRM competencies: A comparative study.” Unpublished Dissertation, Dissertation Abstracts International, 2007.

[6] D. Ulrich, W. Brockbank, A. Yeung, and D. Lake, "Human resource competencies and empirical assessment," Human Resources Management, 34(4), pp. 473-496, 1995.

[7] P. Boselie and J. Paauwe, "Human resource function competencies in European Companies," 2004.

[8] W. Brockbank and D. Ulrich, "Competencies for the new HR: Society for human resource management," Univer- 
sity of Michigan Business School, Global Consulting Alliance, 2003.

[9] J. Kelly and J. Gennard, "The role of personnel directors on the board of directors," Personnel Review, Vol. 25 No. 1, pp. 7-24, 1996.

[10] J. W. Heisler, "Competency today required by today HRM professionals," Link \& Learn eNewsletter. Retrieved November 21, 2007 from World Wide Web: http:// www.hra-nca.org/savedfiles/heisler.pdf , 2003.

[11] A. Mukherjee, "HR transformation-can technology help," Retrieved 23 November, 2007 from World Wide Web: http://www.humanlinks.com/manres/articles/hr_transform ation.htm, 2001.

[12] R. W. Mondy and R. M. Noe, "Human resource management," International Edition, 9th Edition, Prentice Hall, 2005.

[13] P. M. Wright, B. Dunford, and S. Snell, "Human resources and the resource based view of the firm," Journal of Management, 27, pp. 701-721, 2001.

[14] E. E. Lawler and A. M. Mohrman, "Creating a strategic human resource organization: An assessment of trends and new directions. Stanford," CA: Stanford University Press, 2003.

[15] D. Ulrich, "A new mandate for human resources," Harvard Business Review, Vol. 76 No. 1, pp. 124-34, 1998.

[16] M. A. Huselid, S. E. Jackson, and R. S. Schuler, "Technical and strategic human resource management effectiveness as determinants of firm performance," Academy of Management Journal, Vol. 40 No. 1, pp. 171-88, 1997.

[17] S. J. Ramlall, "Identifying and understanding HR competencies and their relationship to organizational practices," Applied
HRM Research, Vol. 11 (1), pp. 27-38, 2006.

[18] M. Losey, "Mastering the competencies of HR management," Human Resource Management, 38(2), pp. 99-103, 1999.

[19] C. D. Johnson and J. King, "Are we properly training future HR/IR practitioners: A review of the curricula," Human Resource Management Review 12(2002), pp. 539-554, 2002.

[20] J. E. Stockman, "Building a quality HR organization at GE," Human Resource Management, 38, pp. 143-146, 1999.

[21] C. M. Giannantonio and A. E. Hurley, "Executive insights into HR practices and education," Human Resource Management Review, 12 (2002), pp. 491-511, 2002.

[22] O. R. Zhan and I. Zakaria, "Strategic HRM: A comparison between selected manufacturing and service firms," Research and Practice in Human Resource Management, 4(1), pp. 43-65, 1996.

[23] L. R. Frey, B. H. Botan, and G. L. Kreps, "Investigating communication : An introduction to research methods," Allyn \& Bacon, Boston, 2000.

[24] F. N. Kerlinger, "Foundation of behaviour research," New York: Holt, Rinehart \& Wiston, Inc., 1973.

[25] D. Ulrich and D. Beatty, "From partners to players: Extending the HR playing," 2001.

[26] W. Brockbank, D. Ulrich, and C. James, "Trends in human resource competencies," Ann Arbor: University of Michigan School of Business,1997.

[27] B. Becker, M. Huselid, and D. Ulrich, "The HR scorecard: Linking people, strategy, and performance," Boston: Harvard Business School Press, 2001. 